This is the author's final, peer-reviewed manuscript as accepted for publication. The publisher-formatted version may be available through the publisher's web site or your institution's library.

\title{
Performance-related specifications for PCC pavements in Kansas
}

Daba S. Gedafa, Mustaque Hossain, Lon S. Ingram, and Rick Kreider

\section{How to cite this manuscript}

If you make reference to this version of the manuscript, use the following information:

Gedafa, D. S., Hossain, M., Ingram, L. S., \& Kreider, R. (2012). Performance-related specifications for PCC pavements in Kansas. Retrieved from http://krex.ksu.edu

\section{Published Version Information}

Citation: Gedafa, D. S., Hossain, M., Ingram, L. S., \& Kreider, R. (2012). Performancerelated specifications for PCC pavements in Kansas. Journal of Materials in Civil Engineering, 24(4), 479-487.

Copyright: @ 2012 American Society of Civil Engineers.

Digital Object Identifier (DOI): doi: 10.1061/(ASCE)MT.1943-5533.0000405

Publisher's Link: http://ascelibrary.org/mto/resource/1/jmcee7/v24/i4/p479_s1

This item was retrieved from the K-State Research Exchange (K-REx), the institutional repository of Kansas State University. K-REx is available at http://krex.ksu.edu 


\title{
Performance-Related Specifications for PCC Pavements in Kansas
}

\author{
Daba S. Gedafa, Ph.D., P.E., M. ASCE ${ }^{1}$; Mustaque Hossain, Ph.D., P.E., F.ASCE ${ }^{2}$; Lon S. \\ Ingram , M.ASCE ${ }^{3}$, and Rick Kreider, P.E.,M.ASCE ${ }^{4}$
}

\begin{abstract}
Statistical specifications for highway construction provide the means to measure the important quality control attributes and ensure their compliance. The pay adjustments in these specifications reflect the amount of pay reduction and the optimized risk distributed between the owner agency and the contractor. The Kansas Department of Transportation (KDOT) has built a comprehensive database of as-constructed properties of materials for Portland Cement Concrete (PCC) pavements from the tests required as part of the Quality Control/Quality Assurance (QC/QA) program. Currently, KDOT pays incentives/disincentives for thickness and strength for PCC pavements. A practical performance model and composite index that include these two quality characteristics (thickness and strength) and air content (for durability) are needed to reflect the combined effect on the performance of PCC pavements. The main objectives of this study were to investigate the effect of levels of significance and lot size, and to develop practical performance model and composite index for PCC pavements in Kansas. Thirteen projects from four administrative districts of KDOT were selected for this study. Statistical Analysis Software (SAS) was used for statistical analysis. Microsoft excel was used to develop the performance models. Lot-wise comparison showed that QC means are significantly different in most of the cases. These cases increase with an increase in significance level. A practical performance model and composite index using quality characteristics (thickness, strength, and air content) have been proposed as an integral part of performance-related specifications (PRS) in Kansas.
\end{abstract}

CE Database subject headings: PRS, composite index, PCC pavements. 
${ }^{1}$ Assistant Professor, Department of Civil Engineering, University of North Dakota, 243

Centennial Drive Stop 8115, Upson II Room 260, Grand Forks, ND 58202-8115. E-mail: daba.gedafa@engr.und.edu

${ }^{2}$ Professor, Department of Civil Engineering, 2118 Fiedler Hall, Kansas State University, Manhattan, KS 66506. E-mail: mustak@ksu.edu

${ }^{3}$ Consultant. E-mail: lon.i@ cox.net

${ }^{4}$ Bureau Chief, Bureau of Materials and Research, Kansas Department of Transportation, 2300

Van Buren, Topeka, KS 66611. E-mail: Rickk@ksdot.org

\section{Introduction}

The history of highway quality assurance has progressed from the early materials and methods specifications through statistical end-result specifications to the current trend toward performance-related specifications (PRS) based on mathematical models and statistical concepts (Weed 2000). Many states have adopted statistical quality control/quality assurance (QC/QA) programs. The properties controlled under such programs should be either related to performance or desirable end-results. These end-result specifications are usually based on statistics from historical construction data (Schmitt et al. 1998; Parker and Hossain 2002). The QC/QA term used by the Kansas Department of Transportation (KDOT) is similar to the one given by the glossary of terms of the Transportation Research Board (TRB), in which quality assurance specifications (QC/QA specifications) are defined as a combination of end result specifications and materials and methods specifications. The contractor is responsible for QC (process control), and the highway agency is responsible for acceptance. In Kansas, KDOT is also responsible for QA (verification). Contractor and KDOT use random sampling and lot-by-lot testing that enables the contractor understand if the operations are producing an acceptable product (TRB 2002).

Many agencies now also include bonus provisions that award payment somewhat in excess of the contract price when the quality level substantially exceeds the level that has been specified 
(NCHRP 1995; Weed 2002; Weed 2005). One of the advantages of statistical specifications is the generation of accurate data from valid random sampling procedures. This data may be analyzed later to improve the specifications further (Afferton 1992).

Some agencies are moving in the direction of PRS that specify the desired levels of key construction quality characteristics that have been found to correlate with fundamental engineering properties that predict performance. When there are different types of tests to be performed on a particular construction item, it can become a complex matter to design an acceptance procedure that is fair, effective, and free from inconsistencies. Composite index avoids certain inconsistencies in practice that may occur with other methods for dealing with multiple quality characteristics. It leads to rational pay schedules in that it assures that all combinations of individual quality measures that predict the same level of expected life will receive the same amount of pay adjustment (Weed 2006).

Pratico (2007) developed a new acceptance model based on mechanical and surface performance of flexible pavements, particularly for porous asphalt concrete pavements. Performance-related specifications based on mechanical and surface performance of Portland cement concrete pavements can be developed as well.

\section{Problem Statement}

The Kansas Department of Transportation (KDOT) has built an impressive database of asconstructed materials properties for Portland Cement Concrete (PCC) pavements from the tests required as part of the Quality Control/Quality Assurance (QC/QA) program. KDOT also has a Construction Management System (CMS) that captures data on selected attributes related to highway construction in Kansas. Burati et al. (2003) have argued that any specification must also be an evolutionary process. Since new information is constantly becoming available in the form 
of additional test results, and as new construction or testing processes are employed, the specification must be continually monitored to see if improvements are needed. Thus a review of the current QC/QA specifications of KDOT is needed to find the opportunities for improvement. This need has also been echoed by the recent FHWA QA Stewardship Review of KDOT with respect to changing level of significance for statistical testing, developing practical performance model, and composite index.

\section{Objectives of the Study}

The objectives of this study were to:

- Investigate any systematic bias in KDOT QC data using moving average control chart analysis,

- Compare lot-and sublot-wise means,

- Analyze the consequences of changing the level of significance from $1 \%$ to $2.5 \%$, and

- Develop practical performance model and composite index.

\section{Test Sections}

Thirteen PCC pavements were selected from four KDOT districts as shown in Table 1. The projects were selected based on availability of large sets of data on PCC strength, thickness, and air content for statistical analysis. Most of the PCC pavements are on interstate highways.

\section{Data Collection}

Random sampling procedures were used to collect QC/QA data for PCC pavements. It is well established that random sampling procedures avoid biases and lead to a more reliable estimate of the as-built construction quality (Weed 1989). 
In Kansas, pay adjustments for pavement thickness and concrete compressive strength are based on the results of tests on cores taken from each lot. All cores for determining strength shall be taken a minimum of 21 days after the pavement has been placed, and in time to determine 28 day compressive strengths. For mainline and other pavements subject to coring for pay adjustments for both thickness and strength, a lot is defined as the surface area of mainline pavement lane placed in a single day. Normally, a lot representing a day's production is divided into five sublots of approximately equal surface area. For high daily production rates (rates exceeding 5,015 square meter per day), the contractor may choose to divide the day's production into two approximately equal lots consisting of five sublots each. Normally one core is taken per sublot (Khanum et al. 2006). Cores are transported to the laboratory as soon as possible and the thickness is measured at three points at approximately $120^{\circ}$ apart. Then the $100 \mathrm{~mm}$ diameter cores are cured to be tested for the 28-day compressive strength.

In general, certified technicians are available on the project site whenever concrete for pavement is being produced and placed. They perform and utilize quality control tests and other quality control practices to assure that delivered materials and proportioning meet the requirements of the mix designs, including temperature, slump, air content, strength, and thickness.

\section{Data for Practical Performance Model and Composite Index}

Burati et al. (2003) concluded that percent within limit (PWL) is well suited as a statistical measure of quality since it has been well studied, statistically unbiased, suitable for both normal and distribution-free (attributes) applications, and works equally well for single-sided or doublesided specifications. To develop practical performance models and composite index, data in 
Table 2 has been used. Acceptable quality level (AQL) has been taken as PWL $=90$ for all quality characteristics based on previous studies (Burati et al. 2003, Weed 2006) whereas different rejectable quality levels (RQL) have been used partly to investigate the effect of different RQL on the models and partly based on the effect of each variable on the performance of the pavement. RQL was taken as PWL=50 for PCC thickness, PWL=40 for PCC strength, and $\mathrm{PWL}=30$ for air content. The expected life (EL) was taken as 20 years when PWL=90 for all quality characteristics whereas EL was taken as 10 years when one of the quality characteristics is at RQL level. These values can be updated based on continuous inflow of QC/QA data, performance data, and/or experience.

\section{Research Methodology}

\section{Comparison of Means}

The F-test in the Analysis of Variance (ANOVA) can signify that not all the means of the levels of the classification variable are the same, but it cannot indicate which means differ from which other means. Comparison methods for means provide more detailed information about the differences among the means (UCDAVIS 2010). Four comparison methods for means have been used at three different significant levels: $1 \%, 2.5 \%$, and 5\%. The comparison methods are described here.

Fisher's Least Significant Difference (LSD) Test: Multiple t-tests are used to compare pairs of means. Fisher's LSD tests is most powerful for finding differences between pairs of means since it does not adjust the significance level needed to achieve significance in order to account for 
multiple testing. As a result, it has the greatest chance of resulting in one or more Type I errors. Type I error is the error of rejecting a null hypothesis when it is actually true.

Tukey's Honestly Significant Difference (HSD) Test: This test is generally recommended when a researcher plans to make all possible pair-wise comparisons since it controls the Type I error rate so that it will not exceed the significance level value pre-specified in the analysis. It maintains an acceptable significance level without an excessive loss of power.

Student-Newman-Keuls (SNK) Test: This test is similar to and/or more powerful than Tukey's HSD. However, it does not control experiment-wise error rate at significance level.

Scheffe's Test: This test is extremely flexible, allowing for any type of comparison. This increased versatility results in less power to detect differences between pairs of groups. It is the most conservative of the unplanned comparison procedures. The test specifies a fixed value of significance level which does not depend on the number of comparisons conducted.

\section{Development of Practical Performance Model (PPM) and Composite Index}

One of the first steps in developing a mathematical model is the choice of model form. Since

most quality characteristics have points of diminishing returns, a model with an "S" shape may be appropriate (Weed 2006). PPM of the form shown by Equation (1) has been developed using data in Table 2. Expected life (EL) was used as a measure of performance (dependent variable) whereas PCC thickness (TH), PCC strength (ST), and air content (VA) were used as independent variables. 
Different shape factors $(\mathrm{C})$ were assumed and simultaneous equations were solved using Microsoft Excel for the model coefficients. Similar procedure was followed to develop composite index using the same independent variables for expected life.

$$
E L=e^{B_{0}+B_{1} P W L_{T H}^{C}+B_{2} P W L_{S T}^{C}+B_{3} P W L_{V A}^{C}}
$$

where EL=expected life; PWL=percent within limit; TH=thickness; ST=strength; VA=air content; $\mathrm{B}_{0}, \mathrm{~B}_{1}, \mathrm{~B}_{2}$, and $\mathrm{B}_{3}=$ model coefficients; and $\mathrm{C}=$ shape factor.

\section{Results and Discussions}

\section{Control Charts}

Microsoft Excel was used to calculate moving averages, average, lower limit, and upper limit. The lower limit and upper limit was taken as minus/plus three times standard deviation $( \pm 3 \sigma)$ of the average, respectively. Fig. 1 shows the control charts for PCC strength and PCC thickness on I-70 in Dickinson County. Fig. 1(a) shows moving averages of QC PCC strength are sometimes lower and higher than the average value but they are within $\pm 3 \sigma$. The moving averages and average are almost equal for most sublots for QC PCC thickness as shown in Fig. 1(b). The moving average is outside $\pm 3 \sigma$ in one sublot only. It is the only point which lies outside the lower and upper limits out of all PCC projects in this study.

\section{Lot-Wise Mean Comparison}

Lot-wise QC mean difference was investigated using four comparison methods at three different significant levels. Significance difference test was summarized as frequency distribution of 
whether lot-wise QC means are similar or not for the different projects in this study. Fig. 2 shows lot-wise mean comparison for PCC strength and thickness using QC data. There is significant difference between lot means in most cases using all methods at all significance levels except Scheffe. This confirms that Scheffe method is the weakest in detecting significant differences. The number of cases with a significant difference in means increases with an increase in significance level. It should be noted that lot-wise QA comparison was not done since there is usually only one QA data per lot.

\section{Sublot-Wise Mean Comparison}

Sublot-wise QC and QA means differences using four means comparison methods at three different significance levels have been summarized as frequency distribution and plotted. Sublotwise QC/QA comparison for PCC thickness and strength has been done using four QC sublot readings and QA reading as the fifth sublot reading in each lot. The fifth QC sublot data has not been used since it was incomplete in some projects. Fig. 3 shows sublot-wise mean comparison for PCC pavements using four mean comparison methods at three different significance levels. Fig. 3(a) shows that significant difference using all methods increases with an increase in significance level for PCC strength. There is no significant difference between sublot means using all methods at all significance levels for PCC thickness except LSD at 5\% significance level as shown in Fig. 3(b). This confirms that LSD is the most powerful method to detect significant differences. Like lot-wise mean comparison, significant difference increases with an increase in significance level. 


\section{Practical Performance Model}

Practical performance model (PPM) for PCC pavements that includes PCC thickness, PCC strength, and PCC air content was developed using data in Table 2. Air content is the property that is traditionally measured, as screening tests, to determine the durability (Diwan et al. 2003, Schell and Konecny 2003). Air content was included in the model development as a surrogate for durability of PCC pavements. The total plastic air content based on concrete after placement behind the paver was used since it gives a better measure of entrained air. Now, nonnormality in the form of skewness and kurtosis can significantly disrupt PWL based pay factor calculations (Uddin et al. 2011). Burati and Weed (2006) also investigated the effect of deviation from normality on the calculation of the PWL by simulating distributions with different skewness levels. Normality tests based on Pearson's Chi-square test, D’Agostino's K-squared test, and the Anderson-Darling should be done before air content is used in performance-related specifications.

Different values of shape factors were tried. The model was checked whether it returns precisely the values used to develop it. It was also checked at extreme values (PWL=100 and PWL=0), and examined how extra quality in one variable can offset the deficient quality in other variable while still producing a design life of 20 years. All checks proposed by Weed (2006) were done in this study.

Checking the Model when Shape Factor, $C=1$ : The model was checked to make sure that it returns precisely the values used to develop it. Table 3(a) shows that the model returns the values used to develop it.

A second test is to check at the extremes, an area in which many models break down. The extremes in this case occur when the individual PWL values are all either 100 or zero percent. 
These results are presented in Table 3(b). When PWL $=100$ in all three quality characteristic, the model predicts that the typical expected life of 20 years will be extended to about 31 years. This is an appreciable increase, but it certainly falls within the experience of many agencies. At the other extreme, the model predicts an expected life less than a year. The model predicts about two years when one of the quality characteristics has PWL=100 and the rest have PWL=0. Although not a frequent occurrence, most highway agencies have experienced this type of result at one time or another. At this stage, there is nothing to indicate the model is unsatisfactory, but several additional tests are required.

The third test is designed to examine how extra quality in some characteristics can offset deficient quality in others while still producing the design life of 20 years. This is an inherent feature in most design methods, and is believed to be an appropriate feature in any model of multiple quality characteristics. However, there would be concern if the model produced a sufficiently low level of quality in any individual characteristic that did not seem consistent with achieving the intended design life, even though the other characteristics were at excellent levels. Table 3(c) suggests that the model may have such a shortcoming. For example, if $\mathrm{PWL}_{\mathrm{TH}}=\mathrm{PWL}_{\mathrm{ST}}=100$, and $\mathrm{PWL}_{\mathrm{VA}}=63$, the model predicts a design life of 20 years. This finding has raised doubts about the efficacy of the model when shape factor is one. It is now appropriate to consider other shape factors. Shape factors: $0.15,0.25,0.5,0.75,1.5$, and 2 were considered. Results from shape factor 0.5 are presented since it was found more reasonable and convenient.

Checking the Model when Shape Factor, $\boldsymbol{C}=0.5$ : As before, the first test of this model is to check that it correctly returns the values of expected life that were used to derive it, which it does. The next check is to repeat the series of tests shown in Table 3 (c) that led to the rejection 
of the simpler model. The equivalent results, obtained with the revised model, are presented in Table 4(a). The values in Table 4(a) seem more reasonable than those obtained in Table 3(c) even though the difference is not significant from a practical point of view.

The next test is to revisit Table 3(b) to check the values obtained at the extremes of PWL= 100 and PWL $=0$. These are presented in Table 4(b) where it is seen that the inclusion of the exponential "C" term has given the revised model a "diminished returns" effect by reducing the maximum predicted life from the previous value of about 31 years to value of about 28 years. The expected value was obtained from Equation (2) using PWL=100 for all quality characteristics.

Further test was conducted. All quality measures decline together. Table 5 shows a very logical progression as the results range from the maximum expected life of about 28 years for excellent quality down to the minimum of less than a year for extremely poor quality. It is believed that most pavement engineers would consider this to be reasonably representative of field experience.

The final PPM is shown by Equation (2). The model is used to better understand the consequences of either exceeding or falling short of the desired quality levels, and to provide a logical and defensible basis for the adjusted pay schedules that are an integral part of PPM. This model can be updated based on continuous inflow of QC/QA data, performance data, and/or experience.

$$
E L=e^{-3.446+0.287 P W L_{T H}^{0.5}+0.219 P W L_{S T}^{0.5}+0.173 P W L_{V A}^{0.5}}
$$

where $\mathrm{EL}=$ expected life PWL $=$ percent within limit; $\mathrm{TH}=\mathrm{PCC}$ thickness; and $\mathrm{ST}=\mathrm{PCC}$ strength. 
Pay Schedule: The performance model serves two purposes. One is to better understand the consequences of either exceeding or falling short of the desired quality levels, and the other is to provide a logical and defensible basis for the adjusted pay schedules that are an integral part of PRS. Ideally, the purpose of the pay schedule is to provide incentive to the contractor to produce the desired levels of quality. Majority of highway agencies often include an additional incentive in the form of small bonus payments to contractors whose extra attention to quality control has produced work that substantially exceeds the acceptable quality levels. At the other extreme, when the desired levels of quality are not achieved, it is the purpose of the pay schedule to recoup for the highway agency the anticipated future losses resulting from poor performance (Weed 2006).

To justify such an approach, there must be a link between quality received and economic gain or loss to the highway agency. Perhaps the most logical and consistent way to establish this link is through the use of life-cycle-cost analysis (Weed 2006). Equation for pay adjustment based on life-cycle-cost analysis was published by previous researchers (Weed 2001, Burati et al. 2003). The authors assumed for the derivation of Equation (3) that moderate deficiencies of construction are not repaired but, instead, lead to premature failure and an earlier scheduling of the next overlay. Values for the constant terms in this equation could be readily obtained.

$$
P A=C\left(\frac{R^{D L}-R^{E L}}{1-R^{O L}}\right)
$$

where $\mathrm{PA}=$ appropriate pay adjustment for pavement or overlay (same units as $\mathrm{C}$ ); $\mathrm{C}=$ present total cost of resurfacing; DL = design life of pavement or overlay; $\mathrm{EL}=$ expected life of 
pavement or overlay (independent variable); OL= expected life of successive overlays (typically 10 years $)$; and $\mathrm{R}=(1+\mathrm{INF}) /(1+\mathrm{INR})$ in which INF is the long-term annual inflation rate and INT is the long-term annual interest rate, both in decimal form.

Equation (2) links quality to performance. It is used to predict the expected life (EL) used in Equation (3). Equation (3) links performance to economic gain or loss. Combining the two equations to link quality to economic effect provide a solid analytical basis for the pay schedule (Weed 2003). It should be noted that Equation (3) was developed for asphalt pavements, but the authors think that it can be used for PCC pavements as well.

\section{Composite Index}

Composite index avoids certain inconsistencies in practice that may occur with other methods for dealing with multiple quality characteristics. It leads to rational pay schedules in that it assures that all combinations of individual quality measures that predict the same level of expected life will receive the same amount of pay adjustment (Weed 2006). To demonstrate the practicality of the composite quality measure, a complete acceptance procedure must be specified. This includes the acceptable quality level (AQL), the rejectable quality level (RQL), the retest provision, and the pay schedule.

Not all individual quality measures are equally suitable for incorporation into a composite measure. Measures that are best suited are those that jointly affect performance in such a way that higher quality in one tends to offset deficiencies in the others, within practical limits. 
Another requirement is that they be convenient to measure in association with each acceptance lot. The example involving strength and thickness of rigid pavement is obviously well suited (Weed 2006). Composite index that includes PCC thickness, PCC strength, and PCC air content was developed in this study. Composite index without and with cross-product of quality characteristics was considered separately.

Without Cross-Product of Quality Characteristics: Composite index (PWL*) was developed in terms of thickness (TH), strength (ST), and air content (VA). The coefficients were obtained using the data in Table (2). The magnitudes of the coefficients reflect the effect of the variables on the long term performance of the pavements. The coefficients may be modified based on continuous inflow of QC/QA data, performance data, and/or experience. Composite index varies from zero to 100\%. The final model developed is shown in Equation (4).

$$
P W L^{*}=0.405 P W L_{T H}+0.324 P W L_{S T}+0.270 P W L_{V A}
$$

where $\mathrm{PWL}^{*}=$ composite index; $\mathrm{PWL}=$ percent within limit; $\mathrm{TH}=\mathrm{PCC}$ thickness; $\mathrm{ST}=\mathrm{PCC}$ strength; and VA= PCC air content.

Pay Schedule: To determine the comparable value of PWL* associated with the AQL, the values of $\mathrm{PWL}_{\mathrm{TH}}=\mathrm{PWL}_{\mathrm{ST}}=\mathrm{PWL}_{\mathrm{VA}}=90$ are substituted into Equation (4) to obtain $\mathrm{PWL}^{*}=90$ as the AQL. Therefore, the pay equation must produce a pay adjustment of zero at $\mathrm{PWL}^{*}=90$. To determine the value of PWL* associated with the RQL, any combination of values that give 10- 
year-life can be substituted into Equation (2). For example, entering $\mathrm{PWL}_{\mathrm{TH}}=72, \mathrm{PWL}_{\mathrm{ST}}=72.5$, and $\mathrm{PWL}_{\mathrm{VA}}=70$ into Equation (4) produces $\mathrm{PWL}^{*}=71.5$. Similarly, any combination of values that gives the 15-year-life produces retest provision. Using $\mathrm{PWL}_{\mathrm{ST}}=82.5, \mathrm{PWL}_{\mathrm{ST}}=83$, and $\mathrm{PWL}_{\mathrm{SM}}=80$ gives $\mathrm{PWL}^{*}=82.0$. Assuming a simple linear pay equation will be sufficient, the pay schedule given by Equation (5) was derived.

$$
P A=1000 P W L^{*}-90,000
$$

where $\mathrm{PA}=$ lot pay adjustment ( $\$ /$ lane-kilometer); and $\mathrm{PWL} *$ = composite quality measure.

When PWL* equals the RQL value of 71.5 , the pay reduction of $-\$ 18,500 /$ lane-kilometer. For truly excellent quality, $\mathrm{PWL}_{\mathrm{TH}}=\mathrm{PWL}_{\mathrm{ST}}=\mathrm{PWL}_{\mathrm{VA}}=100, \mathrm{PWL}^{*}=100$, the pay equation awards a maximum bonus of $\$ 10,000 /$ lane-kilometer. At the other extreme, when $\mathrm{PWL}_{\mathrm{TH}}=$ $\mathrm{PWL}_{\mathrm{ST}}=\mathrm{PWL}_{\mathrm{VA}}=0, \mathrm{PWL}^{*}=0$, the pay equation assigns the maximum pay reduction of $\$ 90,000 /$ lane-kilometer. In between, all pay adjustments are related to performance in that all quality levels that give any particular life will receive the same level of payment.

With Cross-product of Quality Characteristics: Data in Table (6) was used to develop expected life for three variables. Cross-product was included to investigate the difference between only addition and the one which has cross-product. Microsoft excel was used to solve eight simultaneous equations. The final expected life model that includes thickness $(\mathrm{TH})$, strength (ST), and air content (VA) is shown by Equation (6). The model predicts an expected life of about 2.1 year when PWL=0 for all three quality characteristics. Equation (6) was converted into composite index in terms of PWL* as shown in Equation (7). Equation (7) gives PWL* ranging from 0 to $100 \%$. 


$$
\begin{aligned}
& E L=2.066-0.0368 P W L_{T H}+0.0388 P W L_{S T}+0.0721 P W L_{V A}+0.000339 P W L_{T H} \times P W L_{S T} \\
& -0.000401 P W L_{T H} \times P W L_{V A}-0.00180 P W L_{S T} \times P W L_{V A}+0.0000361 P W L_{T H} \times P W L_{S T} \times P W L_{V A} \\
& P W L^{*}=-0.147 P W L_{T H}+0.156 P W L_{S T}+0.289 P W L_{V A}+0.00136 P W L_{T H} \times P W L_{S T} \\
& -0.00161 P W L_{T H} \times P W L_{V A}-0.00721 P W L_{S T} \times P W L_{V A}+0.000145 P W L_{T H} \times P W L_{S T} \times P W L_{V A}
\end{aligned}
$$

where $\mathrm{EL}=$ expected life; $\mathrm{PWL}^{*}=$ composite index; $\mathrm{PWL}=$ percent within limit; $\mathrm{TH}=\mathrm{PCC}$ thickness; ST = PCC strength; and VA=PCC air content.

Pay Schedule: To determine the comparable value of PWL* associated with the AQL, the values of $\mathrm{PWL}_{\mathrm{TH}}=\mathrm{PWL}_{\mathrm{ST}}=\mathrm{PWL}_{\mathrm{VA}}=90$ are substituted into Equation (7) to obtain $\mathrm{PWL}^{*}=72$ as the AQL. Therefore, the pay equation must produce a pay adjustment of zero at PWL* $=72$. To determine the value of PWL* associated with the RQL, any combination of values that give 10year-life can be substituted into Equation (6). For example, entering $\mathrm{PWL}_{\mathrm{TH}}=\mathrm{PWL}_{\mathrm{ST}}=70$, and $\mathrm{PWL}_{\mathrm{VA}}=64.5$ into Equation $(7)$ produces $\mathrm{PWL}^{*}=32$. Similarly, any combination of values that gives the 15-year-life produces retest provision. Using $\mathrm{PWL}_{\mathrm{TH}}=\mathrm{PWL}_{\mathrm{ST}}=81$, and $\mathrm{PWL}_{\mathrm{VA}}=80.5$ gives $\mathrm{PWL}^{*}=52$. Assuming a simple linear pay equation will be sufficient, the pay schedule given by Equation (8) was derived.

$$
P A=1000 P W L^{*}-72,000
$$

where $\mathrm{PA}=$ lot pay adjustment $(\$ /$ lane-kilometer $)$; and $\mathrm{PWL}^{*}=$ composite index.

It can be seen that when $\mathrm{PWL}^{*}$ is at the AQL value of 72, Equation (8) produces a pay adjustment of zero. Similarly, when PWL* equals the RQL value of 32, the pay reduction of $\$ 40,000 /$ lane-kilometer is obtained. For truly excellent quality, $\mathrm{PWL}_{\mathrm{TH}}=\mathrm{PWL}_{\mathrm{ST}}=\mathrm{PWL}_{\mathrm{VA}}=100$, $\mathrm{PWL}^{*}=100$, the pay equation awards a maximum bonus of $\$ 28,000 /$ lane-kilometer. At the other 
extreme, when $\mathrm{PWL}_{\mathrm{TH}}=\mathrm{PWL}_{\mathrm{ST}}=\mathrm{PWL}_{\mathrm{VA}}=0, \mathrm{PWL}^{*}=0$, the pay equation assigns the maximum pay reduction of $-\$ 72,000 /$ lane-kilometer. In between, all pay adjustments are related to performance in that all quality levels that give any particular life will receive the same level of payment.

\section{Conclusions}

Based on this study, the following conclusions can be made:

- Moving average control chart does not clearly show any systematic bias in QC data for PCC pavements in Kansas.

- Student-Newman-Keuls (SNK) and Tukey's Honestly Significant Difference (HSD) show similar results at all significance levels. LSD and Scheffe are the strongest and weakest test, respectively, in detecting significant difference in means.

- The number of cases with a significant difference in means increases with an increase in significance level. It is recommended that $2.5 \%$ be used as significance level as a compromise between 1 and $5 \%$ instead of current $1 \%$.

- The performance model is used to better understand the consequences of either exceeding or falling short of the desired quality levels, and provide a logical and defensible basis for the adjusted pay schedules that are an integral part of PRS.

- Composite index avoids certain inconsistencies in practice that may occur with other methods for dealing with multiple quality characteristics. It also leads to rational pay schedules. Composite index with cross-product of quality characteristics gives a more realistic pay adjustment $(\$ 18,000 /$ lane-kilometer difference) in Kansas.

\section{Recommendations}


Based on this study, the following recommendations can be made:

- It is recommended to validate and/or improve practical performance models and composite index based on laboratory tests, QC/QA data from other part of the region, field performance, and/or experience before starting to use for pay adjustment.

- The models can be used by other agencies that collect similar data after validating the models for their local conditions and/or similar models can easily be developed for the local conditions.

\section{Acknowledgments}

The authors would like to acknowledge the Kansas Department of Transportation for sponsoring this study. Special thanks to Mr. Rick Barzenski, previously with KDOT, Mr. Stephen Morris and Mr. Bill Parcells of KDOT for providing QC/QA data for this study.

\section{References}

Afferton, K.C, Freidenrich, J., and Weed, R.M. (1992). "Managing Quality: Time for a National Policy." In Transportation Research Record: Journal of the Transportation Research Board, No. 1340, Transportation Research Board of the National Academies, Washington, D.C., pp. 3-39.

Benson, P.E. (1995). “Comparison of End Result and Method Specifications for Managing Quality." In Transportation Research Record: Journal of the Transportation Research Board, No. 1491, Transportation Research Board of the National Academies, Washington, D.C., pp. 3-10.

Burati, J.L., and Weed, R.M. (2006). "Estimating Percent within Limits for Skewed Populations." In Transportation Research Record: Journal of the Transportation Research Board, No. 1946, Transportation Research Board of the National Academies, 
Washington, D.C., pp. 71-81.

Burati, L., Weed, R.M., Hughes, C.S. and Hill, H.S. (1995). “Optimal Procedures for Quality Assurance Specifications.” Final Report No. FHWA-RD-02-095, Federal Highway Administration (FHWA), McLean, VA.

Diwan, R.M., Shah, S., and Eggers, J. (2003). "Statistical Quality Control and Quality Assurance Evaluation of Structural \& Paving Concrete.” In Transportation Research Record: Journal of the Transportation Research Board, No. 1861, Transportation Research Board of the National Academies, Washington, D.C., pp. 71-85.

Katicha, S.W., Flintsch, G.W., and McGhee, K. (2011). "Analysis of Variability and Normality Assumption of the VDOT Volumetric Contractor Data.” In Transportation Research Board $90^{\text {th }}$ Annual Meeting Compendium of Paper, Transportation Research Board of the National Academies, Washington, D.C.

Khanum, T., Neil, J. W., Hossain, M., and Ingram, L. S. (2006). "Effect of JPCP Performance on PCC Quality Control/Quality Assurance Specifications.” In Transportation Research Board $85^{\text {th }}$ Annual Meeting Compendium of Papers, CD- ROM, Transportation Research Board of the National Academies, Washington, D.C.

NCHRP (1995). "Performance-Related Specifications for Highway Construction and Rehabilitation." NCHRP Synthesis of Highway Practice 212, Transportation Research Board, National Research Council, Washington, D.C., 1995.

Parker, F. and Hossain, M. S. (2002). "Statistics for Superpave HMA Construction QC/QA Data." In Transportation Research Record: Journal of the Transportation Research Board, No. 1813, Transportation Research Board of the National Academies, Washington, D.C., pp. 151-156. 
Pratico, F.G. (2007). "Quality and Timeliness in Highway Construction Contracts: A New Acceptance Model Based on Both Mechanical and Surface Performance of Flexible Pavements." In Construction Management and Economics, Vol. 25, Issue 3, pp.305313.

Schell, H. and Konecny, J. (2003). "Development of an End-Result Specification for Air Void Parameters Of Hardened Concrete In Ontario's Highway Structures." In Transportation Research Board 82 ${ }^{\text {nd }}$ Annual Meeting Compendium of Papers, CD-ROM, Transportation Research Board of the National Academies, Washington, D.C.

Schmitt, R L, Russell, J.S., Hanna, A.S., Bahia, H.U., and Jung, G.A. (1998). “Summary of Current Quality Control/Quality Assurance Practices for Hot-Mix Asphalt Construction.” In Transportation Research Record: Journal of the Transportation Research Board, No. 1632, Transportation Research Board of the National Academies, Washington, D.C., pp. 2231.

TRB (2002). "Glossary of Highway Quality Terms." Transportation Research Circular No. EC037, Transportation Research Board, National Research Council, Washington, D.C.

UCDAVIS. (2010). Analysis of Variance. www.ctspedia.org/twiki/pub/CTSpedia/ResearchTopics/Analysis_of_Variance _23March_2.docx. Accessed on Nov. 28, 2010.

Uddin, M., Goodrum, P.M., and Mahboub, K.C. (2011). "Severity of Non-Normality in Pavement Quality Assurance Acceptance Quality Characteristics Data and the Adverse Effects on Acceptance and Pay." In Transportation Research Board $90^{\text {th }}$ Annual Meeting 
Compendium of Papers, Transportation Research Board of the National Academies, Washington, D.C.

Weed, R.M. (1989). "Statistical Specification Development." $2^{\text {nd }}$ Edition. Report No. FHWA/NJ-88-017. New Jersey Department of Transportation, Trenton.

Weed, R.M. (2000). "Development of Composite Quality Measures." In Transportation Research Record: Journal of the Transportation Research Board, No. 1712, Transportation Research Board of the National Academies, Washington, D.C., pp. 103108.

Weed, R.M. (2001). "Derivation of Equation for Cost of Premature Pavement Failure." In Transportation Research Record: Journal of the Transportation Research Board, $\quad$ No. 1761, Transportation Research Board of the National Academies, Washington, D.C., pp. 93-96.

Weed, R.M. (2002). "Mathematical Modeling of Pavement Smoothness." In Transportation Research Record: Journal of the Transportation Research Board, No. 1813, Transportation Research Board of the National Academies, Washington, D.C., pp. 159-163.

Weed, R.M. (2003). "Multi-characteristic Performance-Related Specification for Hot-Mix Asphalt Pavement: Complete Development Process." In Transportation Research Record: Journal of the Transportation Research Board, No. 1861, Transportation Research Board of the National Academies, Washington, D.C., pp. 53-59.

Weed, R.M., and Tabrizi, K. (2005). "Conceptual Framework for Pavement Smoothness Specification." In Transportation Research Board 84 ${ }^{\text {th }}$ Annual Meeting Compendium $\quad$ of Papers, CD-ROM, Transportation Research Board of the National Academies, Washington, D.C. 
Weed, R.M. (2006). "Mathematical Modeling Procedures for Performance-related Specifications." In Transportation Research Record: Journal of the Transportation Research Board, No. 1946, Transportation Research Board of the National Academies, Washington, D.C., pp. 63-70. 
Table 1. PCC Pavements Test Sections

\begin{tabular}{ccccc}
\hline Sr. No. & Route & County Name & District No. & Let Date \\
\hline 1 & I035 & Osage & 1 & $07 / 16 / 03$ \\
2 & I035 & Wyandotte & 1 & $12 / 17 / 03$ \\
3 & I035 & Wyandotte & 1 & $01 / 14 / 04$ \\
4 & I035 & Johnson & 1 & $06 / 16 / 04$ \\
5 & I035 & Leavenworth & 1 & $07 / 21 / 04$ \\
6 & I070 & Wyandotte & 1 & $06 / 15 / 05$ \\
7 & I070 & Dickinson & 2 & $07 / 21 / 04$ \\
8 & U054 & Bourbon & 4 & $04 / 16 / 03$ \\
9 & I035 & Coffey & 4 & - \\
10 & U069 & Miami & 4 & $12 / 17 / 03$ \\
11 & U069 & Bourbon & 4 & $06 / 16 / 04$ \\
12 & U054 & Sedgwick & 5 & $01 / 08 / 03$ \\
13 & I135 & Sedgwick & 5 & $07 / 16 / 03$ \\
\hline
\end{tabular}


Table 2. Data for Practical Performance Models and Composite Index

\begin{tabular}{cccc}
\hline \multicolumn{2}{c}{ Percent Within Limit (PWL) for Various Quality Measures } & \multicolumn{2}{c}{$\begin{array}{c}\text { Expected Life } \\
\text { (years) }\end{array}$} \\
\cline { 1 - 3 } Thickness (TH) & Strength (ST) & Air Content (VA) & 20.0 \\
50 & 90 & 90 & 10.0 \\
90 & 90 & 90 & 10.0 \\
90 & 40 & 90 & 10.0 \\
\hline
\end{tabular}


Table 3. Checking the PPM when Shape Factor, $\mathrm{C}=1$ Percent Within Limit (PWL) for Various Quality Measures Expected Life $\begin{array}{lll}\text { Thickness }(\mathrm{TH}) & \text { Strength (ST) Air Content (VA) (years) }\end{array}$

(a) Test of Derivation

$\begin{array}{llll}90 & 90 & 90 & 20.0 \\ 50 & 90 & 90 & 10.0 \\ 90 & 40 & 90 & 10.0 \\ 90 & 90 & 30 & 10.0\end{array}$

(b) Test of Extremes

\begin{tabular}{cccc}
\hline 100 & 100 & 100 & 30.7 \\
100 & 0 & 0 & 2.4 \\
0 & 100 & 0 & 1.7 \\
0 & 0 & 100 & 1.4 \\
0 & 0 & 0 & 0.4 \\
\hline (c) Test of Offsetting Property & & \\
\hline 90 & 90 & 90 & 20.0 \\
75.0 & 100 & 100 & 20.0 \\
100 & 69.0 & 100 & 20.0 \\
100 & 100 & 63.0 & 20.0 \\
\hline
\end{tabular}


Table 4. Checking the PPM when Shape Factor, $\mathrm{C}=0.5$ Percent Within Limit (PWL) for Various Quality Measures Expected Life $\begin{array}{lll}\text { Thickness (TH) } & \text { Strength (ST) Air Content (VA) (years) }\end{array}$

(a) Test of Offsetting Property

\begin{tabular}{cccc}
\hline 90 & 90 & 90 & 20.0 \\
77.0 & 100 & 100 & 20.0 \\
100 & 70.5 & 100 & 20.0 \\
100 & 100 & 63.5 & 20.0 \\
\hline (b) Test of Extremes & & & \\
\hline 100 & 100 & 100 & 28.3 \\
100 & 0 & 0 & 0.6 \\
0 & 100 & 0 & 0.3 \\
0 & 0 & 100 & 0.2 \\
0 & 0 & 0 & 0.0 \\
\hline
\end{tabular}


Table 5. Test of Progressively Poorer Quality Level when Shape Factor, $\mathrm{C}=0.5$

\begin{tabular}{cccc}
\multicolumn{2}{c}{ Percent Within Limit (PWL) for Various Quality Measures } & \multirow{2}{*}{$\begin{array}{c}\text { Expected Life } \\
\text { (years) }\end{array}$} \\
\cline { 1 - 3 } Thickness (TH) & Strength (ST) & Air Content (VA) & 28.3 \\
100 & 100 & 100 & 23.9 \\
95 & 95 & 95 & 20.0 \\
90 & 90 & 90 & 16.7 \\
85 & 85 & 85 & 13.8 \\
80 & 80 & 80 & 11.4 \\
75 & 75 & 75 & 5.7 \\
75 & 50 & 45 & 7.6 \\
65 & 65 & 65 & 6.1 \\
60 & 60 & 60 & 4.9 \\
55 & 55 & 55 & 3.9 \\
50 & 50 & 50 & 3.0 \\
45 & 45 & 45 & 2.3 \\
40 & 40 & 40 & 5.7 \\
75 & 50 & 45 & 1.3 \\
30 & 30 & 30 & 1.0 \\
25 & 25 & 25 & 0.7 \\
20 & 20 & 20 & 0.4 \\
15 & 15 & 15 & 0.3 \\
10 & 10 & 10 & 0.1 \\
5 & 5 & 5 & 0.0 \\
0 & 0 & 0 & \\
\end{tabular}


Table 6. Data for Composite Index with Cross-product Percent Within Limit (PWL) for Various Quality Measures Expected Life

\begin{tabular}{cccc}
\hline Thickness $(\mathrm{TH})$ & Strength $(\mathrm{ST})$ & Air Content $(\mathrm{VA})$ & (years) \\
\hline 90 & 90 & 90 & 20.0 \\
50 & 90 & 90 & 10.0 \\
90 & 40 & 90 & 10.0 \\
90 & 90 & 30 & 10.0 \\
70 & 45 & 35 & 5.0 \\
45 & 65 & 25 & 5.0 \\
30 & 50 & 65 & 5.0 \\
40 & 40 & 55 & 5.0 \\
\hline
\end{tabular}




\section{Figure Legends}

Fig.1. Moving average control chart for PCC pavements. (a) Typical QC PCC Strength, (b) QC PCC Thickness

Fig.2. Lot-wise means comparison for PCC pavements. (a) QC for PCC strength, (b) QC for PCC thickness

Fig. 3. Sublot-wise means comparison for PCC pavements. (a) QC/QA for PCC strength, (b) QC/QA for PCC thickness 